\title{
PACTO DE RESERVA DE DOMINIO Y ENAJENACIÓN A TERCERO ${ }^{1}$
}

\section{Retention of title agreement and alienation to a third party}

Recibido: 28 de agosto de 2019

Aceptado: 26 de noviembre de 2019

\author{
Alejandro Aragón París \\ Becario de iniciación a la investigación del \\ I Plan Propio de Investigación y Transferencia UMA \\ alearapar4b@gmail.com \\ Universidad de Málaga
}

\section{RESUMEN}

El pacto de reserva de dominio constituye uno de los métodos más antiguos de garantía para el aseguramiento del pago total del precio por el deudor. Es una figura en auge y con notable presencia debido a la generalización de las compraventas con precio aplazado y, pese a ello, las referencias legales son escasas. Uno de los mayores inconvenientes que han surgido sobre esta figura ha sido concretar las facultades de disposición sobre el bien objeto de reserva de dominio cuando no se ha completado el pago del precio y, consecuentemente, no es pacífico en la doctrina delimitar su eficacia frente a terceros adquirentes. Por ello, es imprescindible realizar un análisis de las distintas situaciones en que se enajena un bien sobre el cual se pactó una reserva de dominio y, determinar, si tal figura afecta o no al tercer adquirente.

\section{PALABRAS CLAVES}

Reserva de dominio, condición suspensiva, enajenación a tercero, venta de cosa ajena, doble venta, bien mueble, bien inmueble.

\begin{abstract}
The retention of title agreement is one of the oldest methods of guarantee for the assurance of the total payment of the price by the debtor. It is a booming figure with a remarkable presence due to the generalization of sales with postponed price and, despite this, the legal references are scarce. One of the major drawbacks that has arisen over this figure has been to specify the powers of disposition on the object of retention of title when the total price has not been fulfilled and, consequently, it is not peaceful in doctrine to delimit its effectiveness against third parties. It is therefore essential to carry out an analysis of the different situations in where an asset over which retention of title was agreed and determine whether or not such a figure affects the third party acquirer.
\end{abstract}

\section{KEYWORDS}

Retention of title, condition precedent, alienation to third party, sale of another's property, double sale, movable property, immovable property.

\footnotetext{
${ }^{1}$ Este artículo tiene su origen en el Trabajo Fin de Grado correspondiente al Grado en Derecho de la Universidad de Málaga realizado por el autor en el curso 2018/2019, bajo la dirección del profesor Bruno Rodríguez-Rosado, que obtuvo tras su defensa ante el Tribunal la máxima calificación de Matrícula de Honor. Su posterior reelaboración de cara a su publicación se ha llevado a cabo en el marco del Proyecto de Investigación DER201677053-P, del que son investigadores principales los profesores Rocío Caro Gándara y Bruno Rodríguez-Rosado. Mis más sinceros agradecimientos a la Universidad de Málaga y a los mencionados profesores por la ayuda y confianza depositada en mí.
} 
Sumario: 1. Introducción. 2. Construcciones doctrinales sobre el pacto de reserva de dominio. 2.1. Teoría clásica. 2.2. Teoría de la condición resolutoria. 2.3. Tesis de la prenda o tesis Bercovitz. 3. Toma de postura: la teoría clásica o condición suspensiva. 3.1. Argumentos a favor de la teoría clásica. 3.2. Críticas a la teoría clásica. 4. Enajenación por el comprador en caso de pacto de reserva de dominio mobiliaria inscrita por la Ley de Venta a Plazos de Bienes Muebles. 5. Enajenación por el comprador en caso de reserva de dominio mobiliaria no inscrita en la Ley de Venta a Plazos de Bienes Muebles. 5.1. Negocios no inscritos en el Registro de Bienes Muebles por voluntad de las partes. 5.2. Negocios excluidos de la Ley de Venta a Plazos de Bienes Muebles o ajenos a su aplicación. 6. Enajenación por el comprador en caso de reserva de dominio inmobiliaria. 6.1. Reserva de dominio inscrita en el Registro de la Propiedad. 6.2. Reserva de dominio no inscrita en el Registro de la Propiedad. 6.2.1. Tesis dualista. 6.2.2. Tesis monista. 7. Enajenación por el vendedor en caso de pacto de reserva de dominio mobiliaria inscrita por la LVPBM. 8. Enajenación por el vendedor en caso de reserva de dominio mobiliaria no inscrita. 8.1. Negocios no inscritos en el Registro de Bienes Muebles por voluntad de las partes. 8.2. Negocios excluidos de la Ley de Venta a Plazos de Bienes Muebles o ajenos a su aplicación. 9. Enajenación por el vendedor en caso de reserva de dominio inmobiliaria. 9.1. Reserva de dominio inscrita en el Registro de la Propiedad. 9.2. Reserva de dominio no inscrita en el Registro de la Propiedad. 10. Consideraciones finales y conclusiones. Bibliografía.

\section{Introducción.}

Cuando se habla de garantías sobre bienes muebles se repite entre los profesionales del Derecho lo siguiente: "constituye la más enérgica y rápida tutela de los derechos del vendedor", se refiere, simplemente, al llamado pacto de reserva de dominio. Mediante esta obra se pretende, por un lado, esclarecer ciertas nociones fundamentales de una figura tan controvertida como es la reserva de dominio, donde simplemente ya acerca de su naturaleza jurídica hay una profunda división doctrinal; de otro, sentar la eficacia u oponibilidad de tal pacto hacia terceros adquirentes en distintas situaciones que pueden propiciarse dentro de nuestro ordenamiento jurídico.

La elección del pacto de reserva de dominio como eje central de nuestro estudio se debe a diversas razones como puede ser la práctica generalización de las ventas a plazos. Es en este escenario donde el vendedor pretenda emplear algún mecanismo que le permita garantizar el cobro del precio a fin de no quedar en una situación de desprotección. Pues bien, uno de estos mecanismos es la reserva de dominio, pese a la existencia de los derechos reales de garantía -en especial la hipoteca para bienes inmuebles puesta en tela de juicio y debate en los últimos años-. Debe precisarse que la citada cláusula de reserva de dominio muestra una aparición frecuente tratándose de contratos relativos a bienes muebles, en contraposición con los bienes inmuebles.

Independientemente de cual sea el medio de garantía por el que se opte, es innegable que la reserva de dominio a priori manifiesta aspectos que deben ser tenidos en cuenta. En síntesis, a través de esta figura ambos intereses, los de vendedor y comprador, se aseguran: el primero mantiene la propiedad del bien -según la teoría por la que se opteal mismo tiempo que el comprador adquiere la posesión, el goce y disfrute de la misma, inclusive, para el caso de no completarse el precio podrá aquél reivindicar su propiedad o exigir el pago. Se anuncia, en definitiva, la entrada que daba apertura a este trabajo y es 
que el pacto de reserva de dominio sobre bienes muebles "constituye la más enérgica y rápida tutela de los derechos del vendedor".2.

Por otra parte, no debe dejar de atenderse la situación tan especial en la que quedan los intervinientes respecto del bien. A propósito, dictamina el Tribunal Supremo " $\mathrm{La}$ reserva de dominio da lugar a la coexistencia temporal sobre el mismo objeto de dos posiciones jurídico-reales de tipo dominical que son simultáneas, compatibles y reciprocamente recortadas en su contenido: la del vendedor y la del comprador"' ${ }^{\text {. Tal es }}$ la afirmación que los estudiosos del asunto han carecido de concreción a la hora de delimitar el tipo de propiedad o posesión en que quedan las partes, llegándose a decir entre la doctrina, por ejemplo, que el comprador quedaba en una situación posesoria sui generis ${ }^{4}$. Como se puede imaginar este hecho ha propiciado todo un abanico de posturas doctrinales, incluso más complejo en lo referido a las facultades sobre la cosa de ambos.

Partiendo de este punto de partida tan anómalo y dividido en la doctrina respecto de las facultades que ambas partes ostentan sobre el bien, resulta conveniente dilucidar la eficacia de la reserva de dominio sobre las enajenaciones -tanto del vendedor como del comprador- a terceros, en palabras más llanas, concretar si el bien puede ser transmitido a otro sujeto antes de pagarse el precio o de que se resuelva el contrato. Lo anterior ha obligado en este análisis a exponer las diversas interpretaciones que recaen sobre puntos muy candentes y discutidos entre los civilistas e hipotecaristas, tales como los artículos 464, 1124, 1295 o 1473 del Código Civil o los polémicos artículos 32 y 34 de la Ley Hipotecaria, entre otros. Se trata, entonces, de hacer una exposición del significado que tales preceptos pueden acoger, puesto que, en función del significado que se les otorgue, veremos si nos situamos o no ante adquisiciones protegidas e irreivindicables. Todo lo dicho nos permitirá, en última instancia, deducir si el pacto de reserva de dominio es oponible frente a terceros o si éstos quedan protegidos en su adquisición.

En definitiva, se aspira a alcanzar un poco de claridad en todo este panorama tan confuso y fragmentado, es decir, en clarificar cuales son los límites de la eficacia de la reserva de dominio o, por el contrario, cuales son aquellos impedimentos aparentes sobre los cuales esta figura puede imponerse e impedir que tenga lugar un segundo negocio traslativo sobre el mismo bien.

\section{Construcciones doctrinales sobre el pacto de reserva de dominio.}

Comenzando nuestro trabajo debe aclararse que hace ya tiempo que sobre la validez del pacto de reserva de dominio existe, entre doctrina y jurisprudencia, un acuerdo prácticamente unánime en cuanto a su admisibilidad ${ }^{5}$ a raíz del principio de la autonomía de la voluntad, promulgado en el artículo $1255 \mathrm{Cc}$. No obstante, no ocurre lo mismo en lo que respecta a su naturaleza jurídica, donde han surgido diversas teorías en la doctrina sin alcanzar una postura común. Decantarse por una u otra como la correcta es una cuestión trascendental, en la medida que ello va a condicionar aspectos muy significativos sobre tal institución. Por consiguiente, debe comenzarse el objeto de este estudio

\footnotetext{
2 RDGRN de 28 de noviembre de 2017. (Propiedad) (RJ 2017/5680)

${ }^{3}$ STS de 24 de julio de 2012 (RJ 2012/9334).

${ }^{4}$ Pino ABAD, M. (2015), "La cláusula de reserva de dominio en los contratos de venta de bienes muebles con precio aplazado", en Morillas Jarillo, M. J.; Perales Viscasillas, M. y otros (dirs.): Estudios sobre el futuro Código Mercantil: libro homenaje al profesor Rafael Illescas Ortiz. Getafe: Universidad Carlos III de Madrid, pp. 1720-1739. p. 1731.

${ }^{5}$ STS de 10 de junio de 1958 (RJ 1958\2142), STS de 11 de julio de 1983 (RJ 1983\4208) y STS de 19 de mayo de 1989 (RJ 1989\3778).
} 
recogiendo la naturaleza de la reserva de dominio que protege cada posición doctrinal: la tesis clásica, la tesis de la condición resolutoria y la tesis de la prenda.

\subsection{Teoría clásica.}

La llamada tesis clásica o de la condición suspensiva es la que más apoyo y reconocimiento ha encontrado en la doctrina y jurisprudencia. Según esta teoría, a través del pacto de reserva de dominio, el vendedor mantiene la propiedad de la cosa hasta el completo pago del precio por parte del comprador. Una vez que se haya cumplido con el precio, será propietario el comprador.

Sucede entonces que se trata de una condición suspensiva consistente en el abono de la totalidad del precio por la cual, en virtud de la voluntad común de ambas partes, se paraliza o suspende el efecto traslativo de la propiedad. Es importante resaltar que la compraventa en cuestión está perfeccionada, la condición solamente afecta al traspaso de la propiedad, es decir, a su consumación. Esto supone una excepción a la regla general de la teoría del título y modo contenida en el artículo $609 \mathrm{Cc}^{6}$. Entre los defensores de esta doctrina encontramos a MIQUEL GONZÁLEZ o ESPEJO.

\subsection{Teoría de la condición resolutoria.}

La parte de la doctrina que apoya esta posición entiende que la reserva de dominio funciona como condición resolutoria. Así pues, el pacto de reserva de dominio sería la condición resolutoria mediante la cual la propiedad quedará revocada ex tunc si el comprador no cumple con su obligación de pagar el total del precio.

Dicho esto, lo característico de esta construcción es que sí llega a existir una transmisión de la propiedad mediante la teoría del título y modo y, consecuentemente, el comprador es nuevo propietario de la cosa desde la celebración del contrato y entrega de la cosa, si bien sometida a condición. Ello permite que para el caso de incumplimiento el vendedor pueda recuperar la propiedad. Encontramos autores como DíEZ-PICAZO y PEÑA que defienden esta postura.

\subsection{Tesis de la prenda o tesis Bercovitz.}

Finalmente, de acuerdo a la tesis de la prenda se sostiene que la reserva de dominio vendría a funcionar como un derecho real de garantía consistente en una prenda sin desplazamiento o un derecho de hipoteca, según recaiga sobre bienes muebles o inmuebles respectivamente. En relación a los bienes muebles se señalaría que la reserva de dominio "se reduce, al igual que el derecho de prenda, a garantizar el pago del precio por parte del comprador, por lo que no hay razón para concederle mayor eficacia que a éste, de modo que sólo puede ser considerado, pese a su denominación, como un derecho real asimilable a la hipoteca mobiliaria y a la prenda sin desplazamiento de la posesión. En consecuencia, en las compraventas a plazos de bienes muebles con pacto de reserva de dominio el comprador se convierte en propietario de la cosa desde el mismo momento de la entrega y el vendedor o, en su caso, el financiador sólo se «reservan el dominio» a modo y a título de garantía sobre cosa ajena"7. Como principal apoyo e impulsor de este planteamiento aparece BERCOVITZ con seguidores como RIVERA FERNÁNDEZ.

\footnotetext{
${ }^{6}$ Espejo Lerdo de TejadA, M. (2006), La reserva de dominio inmobiliaria en el concurso. Navarra: Civitas. p. 55.

${ }^{7}$ PINO ABAD, M. "La cláusula de reserva de dominio..." Op. cit., p. 1727.
} 


\section{Toma de postura: la teoría clásica o condición suspensiva.}

En el presente apartado únicamente nos vamos a centrar en las principales críticas y apoyos que ha encontrado la tesis clásica por ser la más seguida entre la doctrina y jurisprudencia y la que también a mi juicio es más correcta. Una vez expuestos serán materia de análisis, por constituir el objeto de este estudio, los principales problemas que surgen cuando la cosa en cuestión es transmitida a tercero, tanto por el vendedor como por el comprador, cuando se ha pactado una cláusula de reserva de dominio.

\subsection{Argumentos a favor de la teoría clásica.}

Los apoyos a esta teoría son varios. Primero, cabe aludir a algo tan básico como es su propia denominación "pacto de reserva de dominio" por lo que sin tener que acudir a otra serie de ideas más complejas éste debe concebirse como aquella cláusula por la cual el vendedor sigue manteniendo la propiedad de la cosa objeto del negocio. Esta parece ser la voluntad real de las partes y no debe confundirse ${ }^{8}$.

Y segundo, a mi entender, según esta construcción el pacto de reserva de dominio supone un pacto coherente con los contratos en que se aplaza el precio, pues si el comprador no cumple con su obligación no existe razón de por qué debería hacerlo el vendedor. Al respecto surgen críticas a las que se tratará de dar respuesta más adelante.

Con todo, se aprecian igualmente algunas alusiones legales que apoyan la naturaleza del pacto de reserva de dominio que se explica. Muchas se encuentran en la Ley 28/1998, de 13 de julio, de Venta a Plazos de Bienes Muebles como es el artículo 16.3 y en la Orden de 19 de julio de 1999 por la que se aprueba la Ordenanza para el Registro de Venta a Plazos de Bienes Muebles artículos 4. c), $11.8^{\mathrm{a}}$ o 24 III. También es, por ejemplo, el caso de la Ley 3/2004, de 29 de diciembre, por la que se establecen medidas de lucha contra la morosidad en las operaciones comerciales, en cuyo artículo 10 establece que "En las relaciones internas entre vendedor y comprador, aquél conservará la propiedad de los bienes vendidos hasta el pago total del precio, siempre que se haya convenido expresamente una cláusula de reserva de dominio entre comprador y vendedor antes de la entrega de los bienes [...]”".

Otros ejemplos son la Directiva 2011/7/UE del Parlamento Europeo y del Consejo, de 16 de febrero de 2011, por la que se establecen medidas de lucha contra la morosidad en las operaciones comerciales, que le otorga igualmente tal carácter al pacto de reserva de dominio en su artículo 2. 9) o 9; el Anteproyecto de Ley del Código Mercantil que, pese a no estar aprobado, favorece del mismo modo la interpretación de la tesis clásica de la reserva de dominio en su artículo 512-12 2; o también en el Derecho Foral Navarro se parte de la tesis clásica, concretamente en la Ley 483 del Fuero Nuevo de Navarra.

Por último, como adelantábamos, ha sido la más acogida por la jurisprudencia: en este sentido la sentencia del Tribunal Supremo de 15 de marzo de 1934 ya afirmaba que el pacto de reserva de dominio "consiste en una estipulación expresa de las partes por virtud de la que el dominio de la cosa no se transfiere al comprador mientras no se realice el pago total del precio"'.

Otro ejemplo es la sentencia del Tribunal Supremo de 19 de octubre de 1982 que recogía lo siguiente: "la validez del "pactum reservati dominii» y de su singular eficacia, de que mientras no sea abonado el precio en su totalidad, por acuerdo de las partes, no

\footnotetext{
${ }^{8}$ ESPEJO LERDO DE TEJADA, M. "La reserva de dominio inmobiliaria...” Op. cit., p. 55.

${ }^{9}$ STS de 15 de marzo de 1934 (RJ 1934/462).
} 
se produce el traspaso de la propiedad al comprador, no obstante la entrega de la cosa vendida, dando lugar a una derogación convencional del art. 609, párr. 2. ${ }^{\circ}$, en relación con el 1461 y concordantes, ambos del C. Civ., pacto cuya validez y licitud ha venido proclamando la jurisprudencia desde fines del siglo pasado, en doctrina legal mantenida sin fisuras hasta el día de hoy, como configurador de una venta sometida a la condición suspensiva de que el comprador pague la integridad del precio, condición que una vez cumplida, lo que no consta en el caso ahora discutido, produce «ipso jure» la transferencia del dominio al comprador" 10 .

\subsection{Críticas a la teoría clásica.}

En contraste, encontramos también numerosas críticas que se han realizado a distintos puntos de su construcción. Desde mi punto de vista, gran parte de la determinación de la naturaleza del pacto de reserva de dominio como condición suspensiva casi puede llegar a justificarse simplemente por la carencia de peso en los argumentos que la critican y las propias soluciones que se dan desde esta teoría a las críticas. Todo ello hace, según mi planteamiento, que la utilización de otras posturas para explicar su naturaleza sea forzada y olviden la esencia de este pacto, su función de garantía y el sentido que tiene en los contratos en que se inserta. En cualquier caso, algunas de las objeciones surgidas son las siguientes a las que la doctrina ha tratado de dar respuesta.

En primer lugar, su consideración como un fraude de ley a la prohibición del pacto comisorio (artículos 1859 y $1884 \mathrm{Cc}$ ), pues para el caso de incumplimiento el vendedor adquiere, o mejor dicho conserva, la propiedad del bien vendido que sirve como garantía. No obstante, lo cierto es que la apropiación no se adquiere ipso iure, sino que se necesita la resolución del contrato de compraventa, la devolución de lo percibido (hechas las correspondientes minoraciones) y el ejercicio de las necesarias acciones dominicales para adquirir nuevamente la propiedad plena y no condicionada ${ }^{11}$.

Cabe decir que precisamente contra esta solución han surgido críticas a la propia teoría, pues se pregunta la doctrina que si el vendedor sigue siendo propietario ¿Por qué debe resolver un contrato sobre una cosa que ya le pertenece? De hecho, en mi opinión, este mecanismo sería el correcto, pues no hay que olvidar que el comprador en todo caso adquiere un derecho expectante de propiedad y lo contrario, afirmar que la propiedad sin condiciones se adquiere o vuelve automáticamente en caso de impago, supondría una desprotección hacia el comprador.

Y en segundo lugar, como se dejó ver también se ha planteado la falta de equidad y que es excesivamente favorecedora de los intereses del vendedor en detrimento de los del comprador, crítica fácilmente refutable por lo siguiente. Recuerda MIQUEL GONZÁLEZ que los contratos sinalagmáticos requieren que las prestaciones se realicen de forma simultánea. Consecuencia lógica de ello es que, si se ha acordado un aplazamiento en el precio, el vendedor pueda, e incluso deba, conservar la propiedad para un correcto equilibrio en el negocio jurídico. Es por ello que este autor afirma que "con el pacto de reserva de dominio se restablece la simultaneidad de las prestaciones en la medida correspondiente (pago total del precio- transmisión de la propiedad), por lo que el pacto es conforme con el específico sinalagma funcional, propio de la causa de este tipo de

\footnotetext{
${ }^{10}$ STS de 19 de octubre de 1982 (RJ 1982/5563).

${ }^{11}$ SÁEz RuIZ, J. L. (2015), Tesis doctoral: La reserva de dominio de bienes muebles. p. 140.
} 
compraventa" ${ }^{\prime 2}$. En la misma línea viene PINO ABAD a ratificar el justo equilibrio de los derechos e intereses de comprador y vendedor en las compraventas con precio aplazado a partir de la reserva de dominio ${ }^{13}$.

A continuación se tratará de exponer en los siguientes apartados un examen de los preceptos aplicables y, en base a ellos, los efectos de la reserva de dominio frente a terceros adquirentes -ya sean del comprador o vendedor, a partir de la tesis clásica-, en distintos supuestos que pueden darse dentro del ordenamiento jurídico español.

\section{Enajenación por el comprador en caso de pacto de reserva de dominio} mobiliaria inscrita por la Ley de Venta a Plazos de Bienes Muebles.

En este capítulo, que da comienzo a los distintos escenarios concretos, nos estamos refiriendo a aquellos supuestos en los que el comprador, sin haber completado el pago del precio, enajena a un tercero la cosa sobre la que recaía una reserva de dominio inscrita y que, consecuentemente, es propiedad del vendedor. Como puede apreciarse se trata de una venta de cosa ajena. En este planteamiento los efectos de esta figura son aproblemáticos gracias, entre otros, al artículo 15 de la Ley 28/1998, de 13 de julio, de Venta a Plazos de Bienes Muebles (LVPBM) cuyo tenor que ahora interesa es el siguiente: "Para que sean oponibles frente a terceros las reservas de dominio o las prohibiciones de disponer que se inserten en los contratos sujetos a la presente Ley, será necesaria su inscripción en el Registro a que se refiere el párrafo siguiente. [...]".

El Registro al que se refiere el párrafo siguiente es el Registro de Venta a plazos que hoy día hace referencia al Registro de Bienes Muebles.

Igualmente, en esta línea se encuentra el artículo 4 c) IV de la Orden de 19 de julio de 1999 por la que se aprueba la Ordenanza para el Registro de Venta a Plazos de Bienes Muebles (ORVPBM) que dispone "El comprador de un bien, cuyo dominio se hubiera reservado el vendedor o financiador, carece de legitimación dispositiva y en consecuencia cualquier acto de enajenación o gravamen por él realizado será nulo de pleno derecho. Tampoco podrán ser embargados dichos bienes por deudas del comprador, aunque sí por deudas del beneficiario de la reserva de dominio". Sin embargo, consideramos que se trata de un precepto que contiene una solución demasiada rigurosa y debe ser matizada como se expondrá a continuación.

En síntesis, en este tipo de casos se opta por proteger al vendedor frente a la enajenación realizada por su comprador cuando la reserva de dominio estaba inscrita en el Registro de Bienes Muebles, es decir, la eficacia del pacto de reserva de dominio en estos casos es erga omnes ${ }^{14}$. Su propiedad, la del vendedor, queda asegurada una vez inscrito el pacto, dada su publicidad, de forma que ningún tercero pueda quedar protegido, en virtud del artículo 29 ORVPBM, contra sus acciones reivindicatorias. Así, la enajenación realizada por el comprador a un tercero en que se pretenda transmitir la propiedad plena va a ser nula de pleno derecho. No obstante, tal y como se adelantó, creemos que esta consecuencia que predica el artículo 4 c) de la ORVPBM es excesivamente amplia y que no debería haber obstáculo para que el comprador pudiera disponer de su derecho como tal sometido a condición ${ }^{15}$. En conclusión, en un negocio

\footnotetext{
12 Miquel GonzÁlez, J. M. (2012), "La reserva de dominio", en Bosch Capdevila, E. (dir.): Nuevas perspectivas del derecho contractual. Barcelona: Bosch. pp. 139-224. pp. 175 y ss.

${ }^{13}$ Vid.: PINO ABAD, M. "La cláusula de reserva de dominio..." Op. cit., p. 1728.

${ }^{14}$ RDGRN de 24 de enero de 2005 (Bienes muebles) (RJ 2005\1796).

${ }^{15}$ En este sentido PINO ABAD, M. "La cláusula de reserva de dominio..." Op. cit., p. 1737.
} 
traslativo de dominio lo único que podría transmitir el comprador al tercer adquirente sería una propiedad inestable y expectante del cumplimiento o no del pago del precio ${ }^{16}$.

\section{Enajenación por el comprador en caso de reserva de dominio mobiliaria no inscrita en la Ley de Venta a Plazos de Bienes Muebles.}

Dentro de las enajenaciones realizadas por el comprador de un bien mueble sobre el que se fijó un pacto de reserva de dominio no inscrito deben distinguirse dos supuestos: primero, negocios no inscritos en el Registro de Bienes Muebles por voluntad de las partes; y segundo, negocios no inscritos en el mismo Registro por tratarse de supuestos excluidos o no sujetos a la LVPBM.

\subsection{Negocios no inscritos en el Registro de Bienes Muebles por voluntad de las partes.}

En lo que respecta a los primeros, negocios con reserva de dominio no inscritos en el Registro por quererlo así las partes, pero sujetos a la LVPBM, los efectos guardan relación con el supuesto anterior. No debe olvidarse el carácter imperativo que presenta la LVPBM $^{17}$. Así pues, interpretando el artículo 15 a sensu contrario: si la reserva inscrita protegía al vendedor frente a las enajenaciones del comprador, la reserva no inscrita no le otorga ninguna protección, en principio, frente al subadquirente ${ }^{18}$.

No obstante, la cuestión no es tan simple cuando hay terceros de mala fe. MIQUEL GONZÁLEZ concluye en que el derecho del vendedor prevalece, pese a no estar inscrita la cláusula de reserva de dominio, frente al tercero de mala fe por considerar que en la falta de inscripción rige el artículo 1124 IV Cc. Este precepto hace una remisión al artículo $1295 \mathrm{Cc}$, el cual únicamente protege a terceros que procedan de buena $\mathrm{fe}^{19}$.

En mi opinión, el hecho de que las partes únicamente no hayan querido inscribir el pacto en el Registro de Bienes Muebles no excluye la aplicación de la LVPBM, siempre que el contrato entre dentro de su ámbito de aplicación, y por tanto no supone la aplicación de los efectos del artículo 1124 IV Cc, más aún si se defiende el carácter imperativo de la LVPBM. En cualquier caso, sí que acierto a llegar, aunque por medio de la buena fe como principio general del Derecho, al mismo resultado en donde el tercer adquirente de mala fe no debe quedar protegido frente a las acciones reivindicatorias del vendedor que

\footnotetext{
RIVERA FERNÁNDEZ concreta "Si el vendedor carece de ius disponendi y el comprador, de acuerdo con la tesis clásica, no puede enajenar por no ser propietario, no nos queda más remedio que admitir que estamos ante un bien sustraído al tráfico jurídico. Vulnerando, con ello, un principio esencial en las modernas economias de mercado: el favorecimiento de la circulación de bienes. La consecuencia parece excesiva, sobre todo si se tiene en cuenta que el comprador podría limitarse a transmitir su posición, dejando a salvo el derecho del vendedor" en RIVERA FERNÁNDEZ, M. (1994), La posición del comprador en la venta a plazos con pacto de reserva de dominio. Valencia: Tirant lo blanch. p. 111 y 112.

${ }^{16}$ En este sentido la RDGRN de 17 marzo 2004 (Bienes muebles) (RJ 2004\2389) y la Instrucción de 3 de diciembre de 2002, párrafo $2 .^{\circ}$ del apartado $15 .^{\circ}$, que desarrolla la Instrucción de 23 de octubre de 2001.

${ }^{17}$ STS de 10 de abril de 1981 (RJ 1981\1532), STS de 18 de noviembre de 1983 (RJ 1983\6487) y STS de 12 de diciembre de 1991 (RJ 1991/8996). Aunque en alguna ocasión ha defendido su carácter dispositivo, STS de 19 de septiembre de 1986 (RJ 1986/4714).

18 Alcanza el mismo entendimiento OCAÑA RODRÍGUEZ "Si se trata de bienes muebles, especialmente en el ámbito de la Ley 28/1998, por virtud de lo dispuesto en el artículo 464 CC y artículo 15 (antes artículo 23) de la Ley especial: ni es oponible al tercer adquirente el pacto de reserva de dominio ni tampoco la prohibición de enajenar en tanto no estén inscritos". OCAÑA RODRÍGUEZ, A. (2000), "La reserva de dominio. Naturaleza y efectos más importantes" en Nieto Carol, U. (dir.): La Ley de Venta a Plazos de Bienes Muebles. Valladolid: Lex nova. pp. 139-201.p. 173.

${ }^{19}$ MiQuel GonZÁlez, J. M. "La reserva de dominio” Op. cit., p. 209.
} 
no inscribe la reserva de dominio. Autores como RODRÍGUEZ-ROSADO, al explicar la condena de la mala fe a tenor de otros preceptos, se centra con acierto en la "fuerza expansiva" que presenta este hecho, considerando del mismo modo que el comprador que presenta mala fe no debe quedar protegido pese a la no inscripción ${ }^{20}$. Otros autores ${ }^{21}$ llegan al mismo resultado a partir de la aplicación del artículo $464 \mathrm{Cc}$, de modo que la protección jurídica que otorga tal precepto no se extenderá a aquéllos que procedan de mala fe.

En conclusión, en este primer caso la propiedad del vendedor que por voluntad de las partes no inscriben la reserva vendrá ineficaz frente a los terceros adquirentes del bien mueble de buena fe en caso de enajenación por el comprador. Por el contrario, la reserva de dominio podrá desplegar sus efectos, y consecuentemente ser mantenido el vendedor en su propiedad, cuando el tercer adquirente proceda de mala fe. En este último caso se difiere en la doctrina sobre los medios para llegar a esta solución, aunque afirmar lo contrario sería mantener un resultado injusto difícilmente querido por la Ley.

\subsection{Negocios excluidos de la Ley de Venta a Plazos de Bienes Muebles o ajenos a su aplicación.}

En relación a los segundos, supuestos en donde el contrato queda excluido expresamente del ámbito de aplicación de la LVPBM, o bien directamente no quedan sujetos a la misma, la cuestión se complica más aún.

Teniendo en cuenta el ámbito de aplicación a partir de los artículos 1,2 y 5 de la LVPBM, el siguiente punto de partida es la exclusión de la aplicación de la LVPBM que principalmente, como cabe suponer, determina la aplicación del Código Civil.

Son varios los preceptos que entran en juego para determinar si efectivamente el tercer adquirente del comprador adquiere o no la propiedad del bien objeto de la cláusula de reserva de dominio. Especialmente son los artículos 464 y 1124 Cc y el artículo 85 C. de c., vamos a proceder a su análisis.

\section{2.a. Artículo 464 del Código Civil.}

En relación a las primeras líneas del artículo 464 Cc se han despertado en la doctrina varias teorías sobre las que no existe unanimidad, luego se hace necesario hablar de la función que cumple: "La posesión de los bienes muebles, adquirida de buena fe, equivale al título". Existen pues diversas posturas: la romanista, la germanista y la tesis de la regla especial para la reivindicación mobiliaria. Todas ellas explicadas con mayor detenimiento y ahondamiento por RODRÍGUEZ-ROSADO ${ }^{22}$ que lo expuesto a continuación, donde se resaltarán los aspectos más destacados que propone.

El inicio del artículo 464 Cc se plantea, según la tesis romanista, como la equivalencia de la posesión adquirida de buena fe a un título únicamente válido para la adquisición por usucapión. Como nos recuerda el autor mencionado se debe a que en el Derecho romano la única adquisición a non domino de bienes muebles era la usucapión. Dicho esto, la transmisión por el comprador de la cosa mueble sobre la que recae el pacto de reserva de dominio a un tercero, que pasa a poseerla de buena fe, no conllevaría la transmisión de la

\footnotetext{
${ }^{20}$ RodRígueZ-RosAdo, B. (2009), “"Ius ad rem" y condena de la mala fe: una explicación de los artículos 1473, 1295.2 y 1124.4 del Código civil”. Anuario de Derecho Civil, pp. 1687-1723. p. 1722.

${ }^{21}$ PINO ABAD, M. "La cláusula de reserva de dominio..." Op. cit., p. 1739.

${ }^{22}$ Vid.: Rodríguez-RosAdO, B. (2004), "Cobro de lo indebido, tradición y usucapión: estudio de los artículos 464 y 1897 del Código Civil y 35 de la Ley Hipotecaria". Anuario de Derecho Civil, nº. 3, 10031104. pp. 1055 y ss.
} 
propiedad y únicamente facultaría a éste a usucapirla siempre que concurran el resto de elementos necesarios ${ }^{23}$. No garantiza una adquisición a non domino y la cláusula de reserva de dominio debería seguir desplegando sus efectos al no haber ninguna protección en la adquisición del subadquirente en estos supuestos de venta de cosa ajena, siempre que no transcurra el tiempo necesario para la usucapión.

Para la tesis germanista, línea seguida por nuestra jurisprudencia ${ }^{24}$, el artículo $464 \mathrm{Cc}$ debe interpretarse en el sentido de permitir una adquisición a non domino. Predica el Tribunal Supremo "La más reciente jurisprudencia de esta Sala interpreta que la equivalencia significa titularidad dominical [S. 26-6-1984]; que se sienta la regla de irreivindicabilidad de la cosa mueble cuya posesión se haya adquirido de buena fe, por lo que el inciso primero del párrafo primero del art. 464 del Código Civil se refiere a título de dominio [S. 3-3-1980]; que atendiendo a la interpretación germanista [...]"25. De este modo, quien recibe una cosa mueble, con una posesión de buena fe a título de dueño, adquiere la propiedad incluso en los casos de falta de propiedad del transmitente. Eso sí, esta regla no operaría en los supuestos de pérdida o privación ilegal de la cosa que se posee. Es evidente que parece una interpretación más acorde con la realidad y el ordenamiento actual, el cual permite en supuestos excepcionales una adquisición a non domino confiando en la apariencia, si bien, precisamente por tratarse de acontecimientos extraordinarios y excepcionales ${ }^{26}$ se dice que no se puede interpretar de este modo. Pese a ser un planteamiento muy trascendental a tener en cuenta es cierto que varios autores entienden que esta función es una regla demasiado general que puede no proteger lo suficiente a la propiedad privada (artículo $348 \mathrm{Cc}$ y $33 \mathrm{CE}$ ) y no obedece a una interpretación restrictiva de las adquisiciones a non domino. Esta idea es la que expresa MIQUEL GONZÁLEZ al recordar que "el principio es que el propietario tiene acción para reivindicar y que no pierde su derecho sin un hecho propio (id quod nostrum est sine facto nostro ad alium transferri non potest), a salvo las excepciones establecidas en la

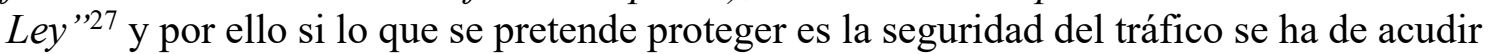
a otros mecanismos o a los supuestos de adquisición a non domino expresamente contemplados. Recapitulando, la consecuencia de esta interpretación es simple, el subadquirente del comprador, siempre que concurra la posesión de buena fe, que supone el título, habrá adquirido la propiedad, quedando despojado de ella el vendedor a pesar del pacto de reserva de dominio, que quedaría sin efectos. Siempre a salvo las excepciones

\footnotetext{
${ }^{23}$ Esta función que se desprende del artículo 464 Cc encuentra mayor apoyo si se hace una interpretación sistemática de varios artículos. Primero, el artículo 1940 Cc que para la usucapión ordinaria exige, entre otros requisitos, un justo título y buena fe; el artículo 1955 que para la usucapión de bienes muebles requiere la posesión de buena fe, por lo que ignora aparentemente el requisito relativo al título dando lugar a una contradicción. Si atendemos al artículo $464 \mathrm{Cc}$ que recoge la equivalencia de la posesión de buena fe al título la contradicción desaparece, adquiriendo sentido la coordinación de aquellos dos primeros artículos, ya que el artículo 1955 Cc exigiría la buena fe e implícitamente también un título. MiQuEL GonZÁlez, J. M. (1993), "Artículo 464 del Código Civil” en Diez Picazo, L.; Bercovitz, R. y otros (dir.) Comentario del Código Civil del Ministerio de Justicia. Madrid: Ministerio de Justicia. Centro de Publicaciones. pp. 12401249. pp. 1241 y 1242.

${ }^{24}$ STS de 26 de junio de 1984 (RJ 1984|3263), STS de 15 de febrero de 1990 (RJ 1990\687) y STS de 25 de febrero de 1992 (RJ 1992\1549).

${ }^{25}$ STS de 25 de febrero de 1992 (RJ 1992\1549).

${ }^{26}$ DíEZ-PICAZO considera también que las adquisiciones a non domino constituyen supuestos excepcionales y por ello la buena fe del subadquirente no puede ser elemento suficiente para corregir la falta de titularidad. No obstante, defiende la ineficacia del pacto de reserva de dominio a través del principio de relatividad de los contratos del artículo 1257 Cc. Díez-PicAzo, L. (2010), Fundamentos del Derecho Civil Patrimonial, volumen IV. Navarra: Civitas. p. 64.

${ }^{27}$ Miquel GonZÁlez, J. M. "La reserva de dominio” Op. cit., p. 197.
} 
del propio precepto, es decir, los casos de pérdida y la privación ilegal, expresión que debe interpretarse en el sentido de robo, robo o abuso de confianza.

Para finalizar también es necesario exponer la deducción a la que llega la tesis de la regla especial para la reivindicación mobiliaria, línea surgida más recientemente que las anteriores e iniciada por VALLET DE GOYTISOLO con ciertas correcciones por MIQUEL GONZÁlEZ y que niegan la existencia de adquisiciones a non domino en base a este precepto. Los defensores de esta posición entienden que el tenor de la primera frase del artículo $464 \mathrm{Cc}$ opera exclusivamente a efectos probatorios en los supuestos de reivindicación mobiliaria. En otras palabras, la posesión de buena fe en concepto de dueño equivale a la prueba del título. Debe tenerse en cuenta que en el tráfico jurídico hoy día es inusual la entrega de documentos que acrediten los negocios sobre muchas de las cosas muebles dificultando la prueba sobre tales operaciones, lo que podría causar un perjuicio al nuevo poseedor al que se le reclama la propiedad ${ }^{28}$. En definitiva, según esta postura, tratándose de un bien mueble sobre el que recayó una cláusula de reserva de dominio, el tercero que adquiere del comprador no recibiría la propiedad, pues tendría título -al poseer de buena fe- sin modo, al carecer de transmisión de propietario. De tal modo que el demandante-vendedor que en una acción reivindicatoria o en una tercería de dominio acreditase la falta de este último extremo podrá recuperar la cosa.

\section{2.b. Artículo 85 del Código de Comercio.}

Al margen de lo dicho, es sabido que existen excepciones en nuestro ordenamiento que habilitan o permiten una adquisición a non domino a través de una protección al tercer adquirente y por ello deben tenerse en cuenta en esta materia, puesto que la reserva de dominio no les será oponible. Supuestos así se encuentran en preceptos de distintos cuerpos normativos como en el artículo 34 de la Ley Hipotecaria o los artículos 85 y 545 C. de c. Es por ello que uno de los preceptos que deben analizarse para determinar también los efectos de la figura objeto de este estudio, no inscrita de acuerdo a la LVPBM, en las transmisiones de una cosa mueble por el comprador a tercero es el artículo $85 \mathrm{C}$. de c., a causa de la remisión hecha por el artículo 464 Cc. En concreto, el artículo 85 C. de c. se refiere a las compras realizadas en establecimientos abiertos al público. El inicio de este artículo es el siguiente: "La compra de mercaderías en almacenes o tiendas abiertas al público causará prescripción de derecho a favor del comprador, respecto de las mercaderías adquiridas, quedando a salvo, en su caso, los derechos del propietario de los objetos vendidos para ejercitar las acciones civiles o criminales que puedan corresponderle contra el que los vendiere indebidamente".

En las compras en almacenes o tiendas abiertas al público, se da como resultado que el pacto de reserva de dominio queda sin efectos frente al tercer adquirente. El vendedor originario no podrá ejercitar la acción reivindicatoria, sin perjuicio de poder acudir a otras acciones para ser resarcido en la pérdida que ha sufrido, aunque su ejercicio únicamente será posible contra el primer comprador. A propósito de lo que se viene diciendo, una sentencia de la Audiencia Provincial de Baleares viene a admitir la venta de cosa ajena en tal supuesto de hecho ${ }^{29}$.

En definitiva, va a ser de vital importancia determinar si estamos ante terceros protegidos en sus adquisiciones, en las cuales las cláusulas de reserva de dominio no van

\footnotetext{
${ }^{28}$ Rodríguez-Rosado, B. “Cobro de lo indebido...” Op. cit., p. 1063.

${ }^{29}$ La SAP Baleares de 20 de septiembre de 2002 (AC 2003\98) aclara la aplicación de este precepto por lo siguiente "La de autos no era una compraventa mercantil sino civil, pero ello no excluye la aplicación del artículo 85 del Código de Comercio ya que el último párrafo del artículo 464 del Código Civil se remite a la legislación mercantil".
} 
a habilitar al vendedor originario para la recuperación de la cosa, siempre a salvo otro tipo de acciones. Además de los preceptos mencionados existen otros casos, como los casos de adquisiciones de buena fe en venta pública o empeños en los Montes de Piedad por los párrafos 2, 3 y 4 del artículo $464 \mathrm{Cc}$ o los supuestos de subasta pública en virtud del artículo 61 de la Ley de Ordenación del comercio minorista, entre otros.

\section{2.c. Artículo 1124 in fine del Código Civil.}

En cualquier caso, procede analizar también la protección del tercer adquirente cuando el vendedor originario se reservó la propiedad, fuera de los supuestos específicamente contemplados. Si no nos encontramos dentro de tales casos debe analizarse el juego de los artículos 1124 IV, 1295 y 1298 Cc.

El artículo 1124 IV Cc al recoger la acción resolutoria finaliza en su párrafo $4^{\circ}$ con lo siguiente: "Esto se entiende sin perjuicio de los derechos de terceros adquirentes, con arreglo a los artículos 1.295 y 1.298 y a las disposiciones de la Ley Hipotecaria”. A continuación, el artículo 1295 Cc señala:

"La rescisión obliga a la devolución de las cosas que fueron objeto del contrato con sus frutos, y del precio con sus intereses [...].

Tampoco tendrá lugar la rescisión cuando las cosas, objeto del contrato, se hallaren legalmente en poder de terceras personas que no hubiesen procedido de mala fe.

En este caso podrá reclamarse la indemnización de perjuicios al causante de la lesión”.

El funcionamiento general de estos artículos no genera problemas. El artículo 1124 habilita a las partes, en obligaciones recíprocas en situación de pendencia, a resolver el contrato ante un incumplimiento grave de la otra parte. Los efectos de la resolución suponen extinguir el contrato, sus obligaciones y proceder a la restitución ex tunc de aquello que se ha recibido.

En una cuestión distinta nos encontramos cuando la compraventa de cosa mueble contiene un pacto de reserva de dominio, pues en estos casos quien es comprador en la primera compraventa y vendedor en la segunda únicamente adquiere y puede transmitir, respectivamente, un derecho expectante y no una propiedad plena. Ello no se debe a la oponibilidad del primer contrato celebrado, sino a las facultades dispositivas que ostenta el comprador-vendedor ${ }^{30}$, sin perjuicio de que si se toma como válida la tesis germanista del artículo 464 quede protegido en su propiedad. No obstante, no hay que dejar de tener presente que una reserva de dominio entre dos contratantes, sin inscripción alguna, únicamente tiene efectos obligacionales entre ellos. No se puede pretender su imposición a terceros que nada sabían de tal cláusula. Ello es lo que dispone el Tribunal Supremo "ese pacto secreto que, cual se ha dicho y como establece la Sentencia de 20 mayo 1982, no vinculan a los terceros, sino exclusivamente en su caso, a los contratantes, a virtud de lo dispuesto en el artículo 1257 del Código Civil; y es que, como también expresa la Sentencia de 5 mayo 1983, el tercero que adquiere una cosa mueble de buena fe (menos aun cuando hay pacto anterior al efecto y disposición que así lo establece) no está afectado por la resolución pactada entre el primero y segundo dueño que la vendió a éste, ni, añadimos ahora, por la condición suspensiva secreta que implica el pacto de reserva de dominio" 31 o en el mismo sentido "No impide que los contratos tengan

\footnotetext{
${ }^{30}$ García Vicente, J. R. (2013), “Artículo 1257 del Código Civil” en Bercovitz Rodríguez-Cano, R. (dir.) Comentarios al Código Civil, tomo VI. Valencia: Tirant lo blanch. pp. 9027-9033. p. 9029.

${ }^{31}$ STS de 26 de mayo de 1995 (RJ 1995\4129).
} 
eficacia indirecta, refleja o mediata para los terceros que han de respetar situaciones jurídicas creadas "32 añadiendo siempre que los terceros tengan "conocimiento efectivo". En esta línea, por tanto, parte de la doctrina y la jurisprudencia sostienen que los terceros adquirentes de buena fe, es decir, que desconocían la existencia del primer negocio, y a título oneroso deban quedar protegidos - todo ello de acuerdo a la tesis germanista que subsanaría la facultad de disposición ${ }^{33}$ - siendo ineficaz la reserva de dominio frente a ellos mediante una extensión del artículo $1124 \mathrm{IV}^{34} \mathrm{o}$ el artículo $1257 \mathrm{Cc}$, entre otros.

\section{Enajenación por el comprador en caso de reserva de dominio inmobiliaria.}

Tratando la figura de la reserva de dominio en bienes inmuebles se aprecia como el panorama es radicalmente distinto. Son varias las causas, desde la aplicación de un cuerpo legal distinto como es la Ley Hipotecaria, con todos sus efectos protectores, a la importancia y la eficacia que el Registro de la Propiedad presenta en la materia tanto en relación a los títulos inscritos como no inscritos. Con la finalidad de simplificar el análisis se dividirán los supuestos en aquellos donde la reserva de dominio se halla inscrita en contraposición con los casos en que no está inscrita.

\subsection{Reserva de dominio inscrita en el Registro de la Propiedad.}

Ya desde la primera Ley Hipotecaria de 1861 se puso de manifiesto un menor o mayor interés en lograr la inmatriculación de las fincas por distintas razones y para ello se otorgaban diversos efectos protectores a quienes operaban según el Registro de la Propiedad. En esta línea también se favorecen aquellas personas que proceden a la inscripción de la cláusula de reserva de dominio que, aunque es poco frecuente en este tipo de negocios, también puede recaer sobre contratos de bienes inmuebles.

Así, podemos ver como el artículo 9 c) LH al hablar de la inscripción establece que se hagan constar "La naturaleza, extensión y condiciones, suspensivas o resolutorias, si las hubiere, del derecho que se inscriba, y su valor cuando constare en el título". Debe recordarse que el Registro de la Propiedad no recoge o publica derechos abstractos, sino que trata de dejar constancia de todas las circunstancias que afecten a tal derecho y tengan una trascendencia real. La trascendencia real ${ }^{35}$ de la reserva de dominio es patente en

\footnotetext{
${ }^{32}$ STS de 12 de julio de 2006 (RJ 2006/6165).

${ }^{33}$ Para el caso de no admitirse la tesis germanista del artículo $464 \mathrm{Cc}$ no tendría sentido acudir a los artículos 1124 ni 1295, dado que al carecer de poder dispositivo el segundo comprador sobre la propiedad plena no podría transmitirla. Así, aunque en relación a un litigio sobre inmuebles, lo expresó el Tribunal Supremo "La última denuncia que se hace de la infracción del párrafo 2. ${ }^{\circ}$ del art. 1295 del Código Civil, al que hace referencia el propio art. 1124, base de la resolución acordada, no es posible que pueda ser apreciada, pues en el caso que estudiamos no concurren las circunstancias que determinan su viabilidad. Se exige para que pueda operar la excepción alli establecida que «el objeto de la devolución se halle legalmente en poder de terceras personas que no hubieren procedido de mala fe». La compraventa en documento privado que efectúa la Comunidad de Partícipes [...] no es más que una venta "a non domino»". STS de 18 de septiembre de 1996 (RJ 199616726).

${ }^{34}$ Aunque alude a bienes inmuebles, sirve de apoyo en cuanto a los efectos del artículo $1124 \mathrm{Cc}$ y terceros.

"En esta materia es fundamental la consideración de que no es oponible la reserva de dominio no inscrita a terceros adquirentes de buena fe. [...] Si se trata de inmuebles inmatriculados, por virtud de lo dispuesto en el artículo 13 y $32 \mathrm{LH}$ y porque, [...] se aplicaría lo dispuesto por el artículo 1124 in fine del CC; no sería preciso siquiera que el comprador de buena fe y a título oneroso inscribiera su derecho para quedar liberado de un gravamen oculto o de una carga resolutoria. [...] Tal subadquirente está protegido en "en derecho civil puro» por la limitación que afecta a las acciones de resolución de los contratos". OCAÑA Rodríguez, A. "La reserva de dominio..." Op. cit., p. 173.

35 "Sin necesidad de entrar en la determinación de la naturaleza jurídica del pacto de reserva de dominio en la compraventa y de la titularidad registral que ostenta el comprador, es indudable que ésta tiene alcance jurídico real” RDGRN de 28 noviembre de 2017 (Propiedad) (RJ 2017/5680).
} 
tanto que sitúa el derecho en una posición de incertidumbre apareciendo dos titularidades: la actual del transferente y la expectante del adquirente. A pesar de todo lo dicho, lo cierto es que la doctrina tradicional ${ }^{36}$ durante una época rechazaba la inscripción de esta figura en base a una interpretación formalista del artículo $11 \mathrm{LH}$, cuestión que ya ha sido superada.

Dicho esto, si las partes finalmente acuerdan la inscripción del pacto de reserva de dominio, el comprador no va a poder transmitir la propiedad plena sobre el bien, pues carece de ella. Por tanto, la compraventa no podría consumarse lo único que podría transmitir sería su derecho de propiedad expectante, por lo que el subadquirente únicamente consigue un derecho condicional como ya se afirmó. En definitiva, el efecto fundamental de esta publicidad registral del pacto de reserva de dominio es nada más y nada menos que sea oponible erga omnes ${ }^{37}$, impidiendo que el tercer adquirente pueda quedar amparado por la fe pública registral del artículo $34 \mathrm{LH}$ y consolidar una adquisición plena, en perjuicio del vendedor primario cuando se ha incumplido la condición, puesto que al anotarse la reserva de dominio se da publicidad a que el titular registral que le transmite carece de poder de disposición pleno. Todo ello en base a que, si el derecho consta con tales afecciones en el Registro de la Propiedad, lo que se transmite es el derecho tal y como consta en el mismo, evitando que tenga lugar una transmisión del derecho pleno protegida por el artículo $34 \mathrm{LH}$, siempre que se den sus requisitos, cuando en la realidad existía una titularidad inestable.

\subsection{Reserva de dominio no inscrita en el Registro de la Propiedad.}

Los verdaderos problemas se plantean cuando la reserva de dominio no ha sido objeto de inscripción por no estar la finca inmatriculada. En estos casos se abre un conflicto entre el título no inscrito del primer vendedor y el título inscrito del tercer adquirente. Así, tratándose de un título no inscrito entra en juego el artículo $32 \mathrm{LH}$, junto con el artículo $606 \mathrm{Cc}$, y de forma ineludible deben tratarse las conocidas tesis monista y dualista, pues los efectos de la reserva de dominio también dependerán de cual se tome como base. Resulta conveniente mencionar aquí el precepto clave, como decimos el artículo $32 \mathrm{LH}$ que dispone "Los títulos de dominio o de otros derechos reales sobre bienes inmuebles, que no estén debidamente inscritos o anotados en el Registro de la Propiedad, no perjudican a tercero". Las divergencias que surgen entre ambas posiciones doctrinales, la monista y la dualista -y los distintos extremos que surgen dentro de esta última- responden a los requisitos que se deben cumplir para hablar de tercero hipotecario y si el tercero al que se refiere el artículo $34 \mathrm{LH}$ es el mismo que el de su artículo 32.

\section{2.a. Tesis dualista.}

Comenzando por el dualismo, este sector de la doctrina parte de la premisa que el tercero que se menciona en el artículo $32 \mathrm{LH}$ es distinto al que se alude en el artículo 34 LH, admitiendo la existencia de una pluralidad de terceros. La consecuencia de esta postura es la defensa de la existencia de dos principios hipotecarios diferentes: el principio de inoponibilidad, recogido en el artículo $32 \mathrm{LH}$, y el principio de fe pública registral, contemplado en el artículo 34 LH. En concreto, es el principio de inoponibilidad el que cobra relevancia y éste se define por GARCÍA GARCÍA como “aquel principio

\footnotetext{
${ }^{36}$ Vid.: AMORÓs GUARDIOLA, M. (1972), "El pacto de reserva de dominio en los bienes inmuebles". Revista crítica de derecho inmobiliario. $\mathrm{n}^{\circ}$. 488, pp. 9-42. pp. 16 y ss.

${ }^{37}$ En este sentido RDGRN de 28 noviembre de 2017 (Propiedad) (RJ 2017/5680).
} 
hipotecario en virtud del cual los títulos de dominio o de derechos reales no inscritos ni anotados en el Registro, no afectan ni perjudican al tercero que inscribió su derecho en el Registro" "38. Sin embargo, lo cierto es que la cuestión va más allá en tanto en cuanto dentro del propio dualismo también existe cierto conflicto acerca de los requisitos exigidos por el artículo 32, encontrando distintas líneas doctrinales que conforman el llamado dualismo extremo, el medio y el moderado. En lo sucesivo simplemente se aludirá a las exigencias de cada una, sin entrar a explicar sus fundamentos con detenimiento por exceder el estudio de este trabajo, y como repercute en la reserva de dominio.

\section{- Dualismo extremo.}

El dualismo extremo está defendido por autores como NúÑEZ LAGOS, TIRSO CARRETERO o GARCÍA GARCÍA. Esta subdivisión interpreta del propio artículo $32 \mathrm{LH}$, que la consideración de tercero únicamente requiere de la inscripción de su derecho, aunque GARCÍA GARCÍA defiende que la buena fe debe ser objeto de una interpretación especial.

El requisito de la propia inscripción del derecho de este tercero se torna esencial por varias razones afirma GARCíA GARCÍA. Primero, el artículo $32 \mathrm{LH}$ al ser un precepto de la Ley Hipotecaria debe referirse a un tercero propio de dicho cuerpo legal, esto es, al que accede al Registro, puesto que precisamente se encarga de regular y contemplar los efectos de aquellos títulos que acceden al Registro. Segundo, en que si su tenor contempla una contraposición y finaliza aludiendo a los títulos no inscritos, indudablemente el tercero del mismo alude a quien los ha inscrito, pues de lo contrario sería una interpretación absurda. Tercero, razona que, si se trata de garantizar la seguridad jurídica y evitar las actuaciones clandestinas mediante la inscripción, ésta debe ser requisito del tercero ${ }^{39}$. En realidad este requisito no debe suscitar controversias, pues es unánimemente admitido.

Por su parte, la buena fe es una exigencia sometida a varias interpretaciones dentro de los defensores de esta postura, aunque realmente autores como NúÑEZ LAGOS o TIRSO CARRETERO la excluyen como condición necesaria para hablar de tercero del artículo 32. Es GARCÍA GARCÍA quien, a pesar de ser dualista radical, alcanza una posición algo más moderada en este aspecto tras una lectura conjunta con el artículo $225 \mathrm{LH}$ "La libertado gravamen de los bienes inmuebles o derechos reales sólo podrá acreditarse en perjuicio de tercero por certificación del Registro". Defiende que, al referirse el último de los preceptos a los supuestos típicos contemplados en el artículo 32 y aludir expresamente a "sólo", la buena fe debería concebirse como aquella apoyada únicamente en la certificación expedida por el Registro, lo que determina que una calificación negativa bastaría para acreditar la buena fe y quedar dentro de la consideración de tercero del artículo 32, que no ampara el fraude ${ }^{40}$.

En consecuencia, tras toda la exposición de esta subdivisión de la llamada tesis dualista se debe volver a conectar con la reserva de dominio para determinar o no su validez frente a terceros dentro de esta interpretación. En estos casos donde se pactó una reserva de dominio que no se ha inscrito en el Registro de la Propiedad y el comprador enajena a su vez el bien inmueble objeto del negocio a un tercero, quedará este último protegido en su adquisición siempre que reúna el siguiente requisito: inscriba su derecho adquirido. De este modo, el tercer adquirente quedaría amparado por el artículo $32 \mathrm{LH}$,

\footnotetext{
38 García García, J. M. (1993), Derecho inmobiliario registral o hipotecario, tomo II. El concepto de tercero. Inoponibilidad. Fe pública. Prioridad. Madrid: Civitas. p. 29.

${ }^{39}$ Ibíd., p. 176.

${ }^{40}$ Ibíd., p. 192.
} 
de forma que su título inscrito prevalecería frente al del primer vendedor (propietario en virtud de la reserva de dominio) que no tenía inscrito su título.

En cualquier caso, es importante resaltar que, si el título del subadquirente no llega a tener acceso al Registro, éste no podrá quedar protegido en su adquisición en cuanto que su transmitente -el comprador- no posee facultades para transmitir la propiedad ${ }^{41}$.

\section{- Dualismo medio.}

El dualismo medio cuenta con defensores como DíEZ-PICAZO o BALLARín MARCIAL $^{42}$. Esta posición defiende que el tercero del artículo 32 debe agrupar dos requisitos: la inscripción de su propio título y buena fe en su actuar ${ }^{43}$, sólo nos dedicaremos a la buena fe como elemento adicional del tercero respecto del dualismo extremo.

Díez-PiCAZO, como seguidor de este requisito ${ }^{44}$ en el funcionamiento del artículo 32 LH, parte de la base que el concepto de buena fe al que alude el artículo 32 es distinto al del artículo 34. Mientras que el segundo se basa en una confianza en el Registro, el primero alude, según entiende, a una buena fe extrarregistral basada en la convicción de un negocio adquisitivo correcto, y por consiguiente, en que su transmitente era verdadero titular con poder de disposición sobre el derecho real. Más aún, también es la creencia en que la cosa está libre de gravámenes y de la inexistencia de otros títulos anteriores ${ }^{45}$.

Por lo tanto, en los supuestos que estamos tratando (enajenación de un bien inmueble, sobre el que recae un pacto de reserva de dominio no inscrito, del comprador a un tercero) la adquisición de la finca por el tercero que inscribe su derecho y ha obrado de buena fe en el negocio adquisitivo supone un título con mayor eficacia respecto del título del primer vendedor que no estaba inscrito. Eso supone que el pacto de reserva de dominio en estos casos carecería de eficacia hacia este tercero.

- Dualismo moderado.

Finalmente hemos de concluir la exposición de las distintas posturas dualistas aludiendo al dualismo moderado, teniendo seguidores como LACRUZ, AMORÓS o VILLARES PICO. Consideran que el tercero contemplado en el artículo 32 LH debe reunir

\footnotetext{
${ }^{41}$ En este sentido lo dispone el Tribunal Supremo respecto de una venta de cosa ajena de un inmueble en la que se pactó en el primer negocio una reserva de dominio: "El negocio precedente celebrado entre el Sr. Miguel Angel y Don Adolfo (comprador y posteriormente vendedor) forzosamente ha de afectar a la capacidad de disposición de este último, de acuerdo con el principio de derecho «nemo plus iuris ad alium transferre potest, quam ipse habet», en virtud del cual, según ha tenido ocasión de reiterar esta Sala, los causahabientes a título particular han de considerarse ligados por los contratos que hubiera celebrado con anterioridad su transmitente que influyan en el contenido del derecho transmitido, reconociéndose jurisprudencialmente el llamado efecto reflejo de los contratos, que viene en ocasiones a mitigar la rigidez del principio de relatividad de los mismos en cuanto a sus límites subjetivos que expresa el artículo 1257 del Código Civil". STS de 14 de octubre de 2003 (RJ 2003\6498).

42 Ballarín Marcial, A. (1949), "El Registro de la Propiedad español. Separata de la «Revista Crítica de Derecho Inmobiliario», por Rafael Núñez Lagos”. Anuario de Derecho Civil, pp. 676-686. p. 685.

${ }^{43}$ Sobre la exigencia de este requisito vid.: GORDILlO CAÑAS, A. (2004), "El principio de inoponibilidad: el dualismo moderado de nuestro sistema inmobiliario registral". Anuario de Derecho Civil, pp. 381-548. pp. 456 y ss.

${ }^{44}$ Entre otros argumentos, sostiene "Para que se sacrifique el derecho válido de un titular, en beneficio de otro titular, que en principio carecería de preferencia, parece necesario que el beneficiario sea persona honesta o no fraudulenta ni aprovechada". DíEZ-PICAZO, L. (2008), Fundamentos del Derecho Civil Patrimonial, volumen III. Madrid: Civitas. p. 542.

45 DíEz-PicAzo, L. (1983), Fundamentos del Derecho Civil Patrimonial, volumen II. Madrid: Tecnos. pp. 391 y ss.
} 
todos los requisitos del tercero del artículo 34 del mismo cuerpo legal, a excepción de la previa inscripción. Por tanto, sus requisitos serían la propia inscripción de su título, la buena fe y debe añadirse la adquisición a título oneroso. Los dos primeros requisitos tampoco van a ser expuestos - pues ya se han dejado algunas líneas de las razones de su exigencia- y este apartado recogerá únicamente las razones de LACRUZ para exigir la adquisición a título oneroso para que opere el principio de inoponibilidad.

LACRUZ defiende la exigencia de la buena fe y la onerosidad tanto en el artículo 32 como en el 34 LH diciendo que "En mi opinión, dados los intereses en presencia en la tutela del tercero, y la finalidad perseguida por la Ley, ambas circunstancias son también exigibles cuando el adquirente resulta protegido en virtud del art. 32 Lh. Ni tendría razón de ser la exención de buena fe y onerosidad en unos casos sí y en otros no, cuando la situación de intereses es la misma en todos. Ninguna de tales circunstancias venía literalmente impuesta por la Ley del 61, pero el argumento principal para exigir la buena fe, es decir, la Exposición de motivos de la Ley, daba a entender claramente que había de exigirse en cualesquiera adquisiciones a non domino: precisamente su texto se refiere más bien a las protegidas por el art. 32. Y si la exigencia de ambos requisitos se añade luego por el legislador al art. 34, siquiera en muy diferentes fechas, no parece que fuera para restringirla a los supuestos de resolución o anulación del título del otorgante: mucho menos en cuanto a la buena fe, que ya se venía exigiendo desde antes de modo general y pese a su falta de expresión legislativa".

"De tales requisitos, finalmente, hay desde la reforma del 44 una mención literal en la ley que parece abarcar cualesquiera casos de adquisiciones a non domino: es el art. 40 cuando limita primero el derecho a solicitar la rectificación del Registro al «titular del dominio o del derecho real que no se ha inscrito" y concluye in fine que "en ningún caso la rectificación del Registro perjudicará los derechos adquiridos por tercero a título oneroso de buena fe durante la vigencia del asiento que se declare inexacto»" "46.

Sea como sea, en definitiva, para esta parte de la doctrina la reserva de dominio carecería de eficacia siempre que el subadquirente cumpliese con los requisitos de la propia inscripción de su título, la buena fe y que haya sido adquirido por un título oneroso. No obstante, esta posición carece de peso en el tema que nos concierne, pues si se pacta una reserva de dominio lo lógico es pensar que se trata de un negocio oneroso, ya que precisamente esta figura trata de garantizar el cobro de la contraprestación.

\section{2.b. Tesis monista.}

Como decíamos, en contraposición con todo lo anterior, se mantiene por cierta parte de la doctrina la llamada tesis monista. Debe zanjarse desde un principio que la tesis monista actualmente se encuentra en declive, siendo que la mayoría de hipotecaristas son partidarios -ya sea en uno u otro grado- de la tesis dualista. Dentro de sus defensores se encuentran autores de prestigio como ROCA SASTRE, SANZ FERNÁNDEZ, JERÓNIMO GonZÁlez, PAU PEDRÓN o PEÑA, entre otros. Por ejemplo, son varias las razones dadas por PEÑA para sostener esta postura: primero, que si el artículo $32 \mathrm{LH}$ ya protege al titular inscrito frente a los títulos no inscritos resulta inútil a efectos prácticos la usucapión secundum tabulas (si se parte de que la inscripción sólo es prueba del título, artículo 35 LH); y segundo, que admitir un resultado idéntico al artículo $34 \mathrm{LH}$ en los casos del artículo 32 sin exigir tantos requisitos supone una opción que atenta en gran medida contra la propiedad ajena y que se muestra en contra de la especial cautela que guarda el

\footnotetext{
${ }^{46}$ Lacruz Berdejo, J. L. y SAncho Rebullida, F. (1984), Derecho inmobiliario registral, elementos de Derecho Civil, III bis. Barcelona: Bosch. p. 192.
} 
artículo 34 al configurar tal escenario como algo excepcional ${ }^{47}$. También contribuye a esta defensa PAU PEDRÓN ${ }^{48}$ justificando que, si nuestro sistema registral realmente pretende fomentar la inscripción de las fincas, al exigir el requisito de la previa inscripción para la aplicación del artículo $32 \mathrm{LH}$ se estimula por partida doble, dado que se exigen dos inscripciones, la del transferente y la del adquirente. Añade, basándose en los antecedentes históricos, que la Ley Hipotecaria de 1861 daba en su artículo 27 una definición de tercero como el que no haya intervenido en el acto o contrato inscrito, ello tras hablar en el artículo 23 (actual 32) de la inoponibilidad, por lo que debía haber un acto o contrato inscrito para poderse hablar de tercero protegido.

Este sector admite sólo la existencia del tercer hipotecario del artículo 34 LH. Por ello, niegan un principio de inoponibilidad como tal desprendido del artículo 32 y dicen que en este escenario sólo puede hablarse de la fe pública registral. En estos casos sería que el aspecto negativo - o de inoponibilidad- de la fe pública registral opera en el artículo $32 \mathrm{LH}$, mientras que el aspecto positivo -o presunción de veracidad y exactitud- se plasma en el artículo 34, y consecuentemente exigen los mismos requisitos ${ }^{49}$.

Los requisitos para PEÑ ${ }^{50}$ y los monistas entonces serían: la adquisición de derechos reales, la buena fe, título oneroso y que el transmitente sea persona que en el Registro aparezca con facultades para transmitir tales derechos, es decir, la previa inscripción. Se omite aquí el análisis de los mismos dado que son igualmente válidos determinados argumentos aportados ya en las exposiciones de las posturas dualistas.

Habiendo aludido de forma sucinta a algunos fundamentos del monismo se observa como en tales casos de venta de cosa ajena, donde la reserva de dominio no fue inscrita en el Registro de la Propiedad, tal acuerdo va a tener efectos frente a terceros, de modo que el subadquirente no va a quedar protegido en su adquisición, ni ésta va a ser oponible frente a la propiedad del vendedor aun sin estar escrito su título (el del vendedor), por carecer del requisito de la previa inscripción. En otras palabras, el subadquirente no se considera de ninguna de las formas tercero hipotecario y el Registro no le brinda ninguna protección pese a la no inscripción de la reserva de dominio.

\section{Enajenación por el vendedor en caso de pacto de reserva de dominio mobiliaria inscrita por la LVPBM.}

Resulta conveniente antes de comenzar a ahondar en las diversas hipótesis que recogen tanto este capítulo como los ulteriores hacer una alusión general. Lo que ahora va a ser materia de análisis son supuestos de doble venta por el vendedor, cuando se estipuló una reserva de dominio en la primera de ellas. En efecto, estamos ante supuestos de doble venta y ello por varias razones. La compraventa se encuentra perfeccionada (artículo $1450 \mathrm{Cc}$ ) pese a la reserva de dominio, figura que únicamente posterga la transmisión de la titularidad dominical hasta el completo pago del precio por el

\footnotetext{
${ }^{47}$ Peña Bernaldo De Quirós, M. (1999), Derecho reales. Derecho hipotecario. Tomo II: derechos reales de garantía. Registro de la Propiedad. Madrid: Civitas. pp. 549 y ss.

48 PAu Pedrón, A. (1993), “Artículo 606 del Código Civil” en Diez Picazo, L.; Bercovitz, R. y otros (dir.) Comentario del Código Civil del Ministerio de Justicia. Madrid: Ministerio de Justicia. Centro de Publicaciones. pp. 1532-1536. pp. 1533 y 1534.

49 Sánchez Calero, F. J. y SÁnchez-Calero Arribas, B. (2015), Manual de Derecho Inmobiliario Registral. Valencia: Tirant lo blanch. p. 161.

50 Vid.: PeÑA BeRnALdo DE QUIRÓs, M. “Derechos reales... II” Op. cit., pp. 554 y ss.
} 
comprador (lo que reiterada jurisprudencia ${ }^{51}$ ha considerado como una derogación convencional de la teoría del título y modo del artículo $609 \mathrm{Cc})$. Así, el vendedor mantiene el derecho de propiedad con ciertas limitaciones sobre el bien, de manera que si procede a venderlo produce una doble venta. En realidad se trata de supuestos más difíciles de encontrar en la práctica, pues se transmite un bien cuya posesión, en virtud de la reserva de dominio, queda en manos del primer comprador, es decir, no la tiene el vendedor.

En estas líneas vamos a comenzar abarcando un escenario ya planteado en el capítulo 4 e ineludiblemente debemos recordar el artículo 15 LVPBM, que viene a preceptuar que para que las reservas de dominio sean oponibles frente a terceros será necesaria su inscripción en el Registro de Bienes Muebles.

Es gracias a la fuerza de la inscripción por la que la enajenación por el vendedor -al igual que la del comprador- carece de problemas o perjuicios para el primer adquirente. Así, el comprador podrá hacer valer su derecho de propiedad expectante (mientras no complete el pago del precio) o su propiedad plena (una vez abonado la totalidad de aquél) frente al tercero que adquirió del vendedor, pues la reserva de dominio inscrita, como se ha visto, es eficaz frente a terceros al no poder alegar éstos desconocimiento.

\section{Enajenación por el vendedor en caso de reserva de dominio mobiliaria no inscrita.}

Al igual que sucedía en su homólogo (capítulo 5), de nuevo es indispensable distinguir la causa de no inscripción del pacto, pues las consecuencias jurídicas son distintas.

\subsection{Negocios no inscritos en el Registro de Bienes Muebles por voluntad de las} partes.

Cuando la reserva de dominio no se inscribió en el Registro de Bienes Muebles y el bien se vende a un tercero por el propio vendedor (igual que cuando es el comprador quien vende el bien) se trata de un caso en que, a nuestro juicio, procede una interpretación a sensu contrario del artículo 15 LVPBM. Según ésta, la reserva de dominio no inscrita carecería de efectos frente a terceros cuando las partes tuvieron la oportunidad de inscribirla y no lo hicieron. En consecuencia, la falta de inscripción opera a favor de los terceros, de modo que quedarían protegidos en su adquisición los segundos adquirentes del vendedor por no serles oponible la reserva de dominio.

No obstante, de nuevo surge la controversia sobre si esta ausencia de inscripción favorece también a las adquisiciones efectuadas por compradores de mala fe. En una línea similar que la adoptada por la doctrina cuando la enajenación se hacía por el comprador, y con el fin de evitar prácticas fraudulentas, parece que lo conveniente es que la reserva de dominio únicamente sea ineficaz ante terceros de buena fe. Los terceros que procedan de mala fe no deberían quedar amparados en su adquisición, ya sea por aplicación del artículo 1473 I o por analogía del artículo 464 ambos del Código Civil, este último en el sentido de no querer subsanar los defectos de titularidad o disposición a favor de terceros de mala fe.

\footnotetext{
${ }^{51}$ STS de 19 de octubre de 1982 (RJ 1982/5563), STS de 19 mayo 1989 (RJ 1989\3778) y STS de 12 de marzo de 1993 (RJ 1993/1794).
} 


\subsection{Negocios excluidos de la Ley de Venta a Plazos de Bienes Muebles o ajenos a su aplicación.}

Fuera de la aplicación de la LVPBM los supuestos de doble venta se resuelven por el párrafo primero y tercero del artículo $1473 \mathrm{Cc}$ que atiende expresamente a ellos. Debe resaltarse aquí que, aunque este precepto venga a solucionar los problemas derivados de la doble venta, para algunos autores se levanta cierta inconsistencia, que trataremos de explicar, en relación a la tesis clásica que defendemos.

El citado artículo en su párrafo primero dispone que "Si una misma cosa se hubiese vendido a diferentes compradores, la propiedad se transferirá a la persona que primero haya tomado posesión de ella con buena fe, si fuera mueble". Sabemos que es normal que en las ventas con reserva de dominio el comprador adquiera la posesión pero no la propiedad. Planteado así el supuesto de hecho RIVERA FERNÁNDEZ afirma que se produce un efecto extraño, señalando que "Sin embargo, no podemos dejar de destacarlo, dicho artículo hace una atribución directa de la propiedad al poseedor del bien. En tal caso, no sólo no apreciaríamos la efectividad de la reserva practicada por el vendedor; sino que incluso comprobaríamos que el comprador-poseedor-adquiere la propiedad del bien por un acto unilateral del vendedor (la doble enajenación), independientemente de que se satisfaga el pago total del precio" "52. En mi modesta opinión creo que afirmar estas consecuencias supone hacer una interpretación demasiado estricta del precepto y en todo caso abstraída de los efectos de la reserva de dominio. Si por un lado hemos afirmado que la reserva de dominio no transmite la propiedad hasta el completo pago del precio por el comprador, este precepto únicamente viene a establecer un criterio de preferencia en la doble venta. No se trata de una norma que venga a determinar cuando se consuma o no la venta y, por tanto, se produzca el traslado del dominio. Es una regla que conectándose con la reserva de dominio debería interpretarse del siguiente modo: si una misma cosa se hubiese vendido a diferentes compradores habiéndose pactado en cualquiera de ellas una reserva de dominio, la propiedad se transferirá a la persona que primero haya tomado posesión de ella con buena fe siempre que se cumplan el resto de condiciones necesarias para su consumación, si fuera mueble.

En cualquier caso, el artículo 1473 Cc viene a sentar que será preferido en la propiedad el comprador que primero tome posesión de buena fe del bien mueble frente al que no lo hizo. Esta norma supone entonces afirmar implícitamente los efectos de la reserva de dominio frente al segundo comprador si la compraventa en que se pacta va a ir siempre acompañada del traspaso posesorio. Igualmente, para el caso improbable en que no tuviese lugar el traspaso posesorio la regla subsidiaria contenida en el párrafo tercero va a atribuir de la misma forma la propiedad al primer comprador, ya que el criterio de preferencia es la tenencia del título más antiguo también en bienes muebles.

\section{Enajenación por el vendedor en caso de reserva de dominio inmobiliaria.}

\subsection{Reserva de dominio inscrita en el Registro de la Propiedad.}

Se engloban en esta sección las hipótesis en que un vendedor, en una primera compraventa inscrita en el Registro vende con pacto de reserva de dominio una finca a un sujeto y a continuación, en otro negocio distinto, vende a un segundo comprador el mismo inmueble.

\footnotetext{
${ }^{52}$ RiVERA FernÁNDEZ, M. “La posición del comprador...” Op. cit., p. 106.
} 
Según el planteamiento que hemos dispuesto no puede ser de otra manera que la reserva de dominio efectivamente debe poder desplegar sus efectos erga omnes. Se debe a que una vez inscrita la reserva, el segundo adquirente del vendedor no va a poder alegar desconocimiento o falta de publicidad de aquella condición con el fin de que no le sea oponible. Por tanto, es cierto que se puede concluir que la segunda compraventa es válida si bien, no puede transmitir la propiedad plena, pues se tiene título pero no modo, dado que el vendedor no es propietario de ese derecho en tal estado o plenitud que se pretende transmitir. Lo que realmente se está transmitiendo -o mejor dicho, podría transmitirse- es otro derecho condicional pendiente del abono o no del precio.

Ello supone que, al igual que sucedía anteriormente en la enajenación realizada por el comprador, al estar inscrita la primera compraventa con su reserva de dominio, la persona que le transmite -el vendedor- no tiene facultad de disposición sobre el derecho que le está concediendo (propiedad plena), sino sólo sobre una propiedad inestable sometida a condición. Es decir, la falta de modo no va a poder ser subsanada por el artículo $34 \mathrm{LH}$, pues no se estaría protegiendo así la apariencia registral, sino más bien lo contrario al no recibir de una persona que tenga a su favor inscrito tal derecho. El Tribunal Supremo en la resolución de un litigio distinto a la cuestión aquí planteada admite, a modo ejemplificativo, la oponibilidad de la reserva de dominio frente a terceros una vez inscrita "En consecuencia, lo que importa para la transmisión del dominio mediante compraventa no es el pago del precio, sino que el contrato o acuerdo de voluntades venga acompañado de la tradición en cualquiera de las formas admitidas en derecho. Para que no sea así, esto es para que el impago de todo o parte del precio pueda influir en la transmisión del dominio, será preciso que así se haya pactado expresamente en el propio contrato de compraventa, ya mediante una reserva de dominio a favor del vendedor, ya mediante una condición resolutoria, cuya respectiva constancia registral sí afectará al tercero del artículo 34 de la Ley Hipotecaria" ${ }^{23}$. Consecuentemente, el tercero-segundo comprador no va a poder ampararse en la protección de una adquisición a non domino que le brindaría la fe pública registral a través del artículo $34 \mathrm{LH}$, pues la inscripción de la reserva de dominio opera en favor de los derechos que le pudieran corresponder tanto al vendedor como al comprador ${ }^{54}$.

\subsection{Reserva de dominio no inscrita en el Registro de la Propiedad.}

La doble venta en la que la reserva de dominio acordada en la primera no se ha inscrito en el Registro de la Propiedad, en principio, es ajena a la regulación de la Ley Hipotecaria y supletoriamente ha de acudirse al Código Civil.

Al igual que sucedía con las dobles ventas sobre bienes muebles sin inscripción de la reserva, la misma cuestión sobre inmuebles se regularía también por el artículo $1473 \mathrm{Cc}$. En los negocios sobre inmuebles se contemplan tres criterios con aplicación subsidiaria. El primero de ellos, recogido en el párrafo segundo, atribuye la propiedad al adquirente que antes la haya inscrito en el Registro. El supuesto es el siguiente: nos estamos refiriendo al contexto en que un único vendedor enajena un bien inmueble con reserva de dominio no inscrita a un primer comprador y posteriormente enajena a otro comprador que se adelanta en la inscripción en el Registro de la Propiedad. Dicho esto, la solución es simple, si el segundo adquirente inscribe su derecho de propiedad con antelación al primer comprador, aquél será preferido en la propiedad siempre que concurra buena fe requisito que la jurisprudencia exige para la aplicación del artículo $1473 \mathrm{Cc}$ pese a no ser

\footnotetext{
${ }^{53}$ STS de 7 de septiembre de 2007 (RJ 2007\5303).

${ }^{54}$ En el mismo sentido. RIVERA FERNÁNDEZ, M. "La posición del comprador...” Op. cit., p. 105.
} 
expreso-, quedando la reserva de dominio sin eficacia frente a nuevos adquirentes por la ausencia de inscripción. No obstante, a esta misma solución ciertamente podría llegarse mediante la aplicación del artículo $32 \mathrm{LH}$ de acuerdo al dualismo medio o moderado. Como decimos, tal regla del artículo $1473 \mathrm{Cc}$ podría carecer de sentido ${ }^{55}$, puesto que ya el artículo $32 \mathrm{LH}$ recoge que el título de propiedad del comprador que primero accede al Registro, concurriendo la buena fe, va a primar sobre el primero que no inscribió, aun cuando hubiera pactado una reserva de dominio.

A pesar de la solución expuesta, que sería la seguida por la mayoría de la doctrina, nosotros queremos plasmar otro planteamiento como solución al conflicto de títulos en el que nos ubicamos. Esta solución pasa por distinguir si en el caso concreto la finca se encuentra o no inmatriculada. Primero vamos a aludir al caso en que se hallase inmatriculada la finca (recordemos, vendida en una primera ocasión con reserva de dominio no inscrita y posteriormente enajenada de nuevo): en ella, el vendedor en la segunda venta pretende transmitir un derecho de propiedad como pleno, sin sujeción a eventuales condiciones, cuando realmente tiene una propiedad inestable. En este caso consideramos que no es necesario acudir al artículo $1473 \mathrm{Cc}$, o mejor dicho, podría ser aplicable preferentemente el artículo $34 \mathrm{LH}$ por encontrar una mejor cabida aquí ${ }^{56}$. Si se analiza el precepto se observa como el segundo comprador reúne los requisitos: el hecho de haber recibido un derecho de persona que aparecía en el Registro con facultades de transmitirlo (la reserva de dominio, pese a no estar inscrita, supone una limitación en las facultades de disponer del vendedor), un título oneroso, la buena fe y la inscripción de su derecho. Debe ser objeto de aclaración que en este caso el artículo 34 LH no opera en el sentido de permitir una adquisición a non domino, ya que el vendedor es propietario de la cosa gracias a la reserva de dominio según la tesis clásica. Aquí, el artículo 34 LH, funciona como medio subsanador de la falta de facultades dispositivas del vendedor ${ }^{57}$, limitación que le viene impuesta por el propio pacto de reserva de dominio, y en consecuencia dicho artículo sirve también como instrumento para impedir que la reserva

\footnotetext{
${ }^{55}$ Argumenta GARCÍA GARCÍA "Y ello porque el artículo 1473.2 Cc, en sede de doble venta, no es más que una aplicación del criterio general de los artículos 606 Cc y 32 LH y no un precepto exclusivo para la doble venta. Que el artículo 1473.2 Cc es un precepto «derivado» de la regla general del artículo $32 \mathrm{LH}$ y no al revés, se ve muy claro en el Proyecto de Código civil de 1851, en el que el texto del artículo 1396 decía: Si una misma cosa hubiese sido vendida a dos diferentes compradores, se estará a lo dispuesto en el artículo 982”. GARCÍA GARCÍA, J. M. “Derecho inmobiliario... II” Op. cit., p. 182 y ss. En sentido contrario los autores monistas, ya que para la aplicación del artículo 32 LH se exige la previa inscripción. PAu Pedrón, A. “Artículo 606...” Op. cit., p. 1535. Asimismo, parten de que la alusión "al que primero inscriba" supone un reenvío completo a la Ley Hipotecaria, requiriendo todos los requisitos del artículo 34 LH, sin que en ningún caso quepa entender que el artículo $1473 \mathrm{Cc}$ consolida una adquisición a non domino distinta de la hipotecaria. SABORIDO SÁNCHEZ, P. (2008), Reflexiones sobre el tercero hipotecario. Madrid: Centro de Estudios Registrales. p. 132.

${ }^{56}$ A una idea similar concluye ALBALADEJO aclarando que "Por lo que respecta al caso de que lo vendido sea un inmueble, el Código, en el artículo 1473, quiso acoplarse a la Ley hipotecaria. Independientemente de que lo consiguiera o no totalmente, con arreglo al texto entonces vigente de ésta, es lo cierto que, a tenor del que hoy rige, ambos -Código y L.H (cfr. Su art. 34)- recogen la misma posición: protegen en su adquisición al que de buena fe ha comprado (adquirido a título oneroso) una cosa a quien en el Registro de la Propiedad aparece con facultad para transmitirla y ha inscrito en el mismo su adquisición, prefiriéndolo sobre aquel otro comprador que, incluso habiendo recibido realmente la cosa con anterioridad, no llegó a inscribirla a su nombre”. Albaladejo García, M. (2011), Derecho Civil II. Madrid: Edisofer. p. 568.

57 "Si el título es inválido, el tercero adquirente no resultará protegido por la fe pública registral, ya que el único defecto que sana el Registro es el defecto de titularidad o la falta de facultades dispositivas en el transferente”. SÁnchez CAlero, F. J. y SÁnchez-CAlero Arribas, B. "Manual de Derecho...” Op. cit., p. 159.
} 
de dominio sin publicidad afecte a terceros. De este modo, se podría afirmar que el segundo comprador "adquiere inmediata y definitivamente el derecho que figuraba inscrito como perteneciente a su transmitente y en los términos en que el Registro lo publicaba. [...] así ocurre cuando dicha titularidad se publica como estable o firme, aunque en la realidad sea una titularidad inestable o claudicante" 58 , es decir, adquiriría un derecho de propiedad plena a través de la inscripción.

De acuerdo a lo anterior, el juego del artículo 1473 Cc quedaría limitado a los supuestos de doble venta por el vendedor, en que carece de inscripción la reserva de dominio de la primera venta, y la finca no se hallaba inmatriculada. En consecuencia, al no reunir el segundo comprador el requisito de recibir un derecho que constase previamente inscrito no podría quedar amparado por el artículo $34 \mathrm{LH}$ y debería acogerse al criterio de preferencia del artículo $1473 \mathrm{Cc}$-o como se ha dicho, también por el artículo $32 \mathrm{LH}-$, es decir, adquirirá la propiedad el segundo vendedor siempre que inscriba su derecho en el Registro y proceda de buena fe, siendo ineficaz la reserva de dominio no inscrita.

Planteamiento distinto surge en el caso en que ninguno de los compradores haya inscrito su derecho, es entonces cuando debe acudirse al criterio subsidiario del artículo 1473 III Cc. Sucede que el citado precepto atribuye la propiedad al primero que tome posesión del inmueble de buena fe. Esto, como se comentó, es considerar la eficacia de la reserva de dominio frente al segundo comprador implícitamente, ya que no hay que olvidar que esta figura se establece precisamente con la intención de entregar la posesión sin transmitir la propiedad. No obstante, con el fin de no caer en interpretaciones rigurosas debemos recordar que no es una adjudicación automática de la propiedad, sino que el primer comprador adquirirá el inmueble una vez pagado el precio.

Por último, recoge el precepto in fine que, faltando la inscripción del comprador y la toma de posesión de buena fe, será propietario quien el de título más antiguo con buena fe. Por tanto, en aplicación de estos dos últimos criterios subsidiarios se opta por proteger al primer comprador en cuya compraventa se pactó la reserva de dominio, aunque resaltamos que lo cierto es que no le atribuye la propiedad a causa de la reserva de dominio, pues si ésta no se hubiese pactado tendría igualmente la propiedad.

\section{Consideraciones finales y conclusiones.}

Tras todo lo expuesto resulta conveniente plasmar, para concluir este trabajo, una valoración en conjunto del análisis elaborado y de las ideas extraídas del mismo.

Partiendo de la propia reserva de dominio y su indudable función de garantía se concluye que, pese a ser una figura cuya validez fue admitida desde antaño, ha carecido de una regulación legal completa, o cuando menos extensa, pues únicamente se encuentran alusiones a su concepto en la mayoría de los casos. Todo ello en una actualidad en la que la generalización de ventas a plazos promete un auge de esta figura. Resulta entonces criticable la indiferencia del legislador en esta materia, más aun cuando nos podemos atrever a decir que existe una jurisprudencia bastante extensa de nuestro Tribunal Supremo como para afirmar sin fisuras la naturaleza de la reserva de dominio como condición suspensiva de acuerdo a la tesis clásica. Posición que personalmente también apoyo por ser la función más acorde con su finalidad y el tipo de contratos en que se inserta, además de los argumentos ya dados. En cualquier caso, las escasas referencias legales han desencadenado un vacío normativo, colmado de no pocas

\footnotetext{
${ }^{58}$ Ibíd., p. 164.
} 
opiniones doctrinales que provocan que, a día de hoy, pervivan aun latentes controversias sobre su naturaleza jurídica, con todo lo que ello conlleva. Consecuencia de lo anterior sucede que las dificultades de esta figura se extienden al poder de disposición de las partes, dando lugar a una falta de claridad sobre sus efectos en los casos en que vendedor o comprador disponen del bien a favor de un tercero.

Para poder dilucidar las facultades de disposición se ha visto como entran en juego multitud de preceptos sobre los que existen distintas interpretaciones y, no solo eso, sino que cada una de ellas otorga un alcance distinto a los efectos de la reserva de dominio para con terceros. Pese a lo anterior no debe olvidarse que no hay obstáculo a que -en todas y cada una de las hipótesis a las que nos hemos referido- tanto vendedor como comprador enajenen su titularidad in fieri, es decir, en los términos propios en que ostentan su derecho sometido a condición. Esto es lógico, ya que entendemos que en tales casos no se lesionan los derechos de tercero. Por ende, la titularidad del derecho del tercer adquirente quedará expectante al cumplimiento o incumplimiento del pago del precio. Igualmente claro es que la propia reserva de dominio como tal, sin publicidad, difícilmente pueda ser oponible frente a terceros, el efecto protector que se desprende, frente a todos, es que el mantenimiento de la propiedad en manos del vendedor impida al comprador disponer de ella mediante la regla "nemo plus iuris ad alium transferre potest, quam ipse habet", a salvo las excepciones.

Así, otra valoración que se predica de lo anterior es que la creación de los Registros, en especial el de Bienes Muebles y el de la Propiedad, ha supuesto un hito en la materia gracias al otorgamiento de publicidad a determinados negocios, como bien es la figura de la reserva de dominio, posibilitando su oponibilidad frente a terceros. Tanto es así que se aprecia como aquellos escenarios en que la reserva de dominio se inscribe carecen de problemas. En mi opinión, ello hace que se puede afirmar tajantemente que los registros públicos cumplen con su función de garantizar la seguridad jurídica, tal y como hemos puesto de manifiesto.

En sentido contrario, cuando falta la inscripción, ponemos de relieve la profunda división doctrinal acerca de preceptos sumamente fundamentales en el sistema de transmisión de la propiedad y, lo cierto, es que ello consideramos que no debe pasar desapercibido. Aquí queremos resaltar una posición a favor de varios aspectos.

Primero, un apoyo a la tesis germanista del artículo 464 y, consecuentemente, a las adquisiciones a non domino por virtud de este precepto dejando sin efecto la reserva de dominio sin publicidad, salvas las excepciones contenidas. Es indudable que la propiedad es un pilar básico de todas las economías, pero igualmente importante, o más, es el fomento del tráfico jurídico de los bienes. Resulta entonces que con la tesis germanista se favorece este fenómeno, siempre a favor de aquellos terceros que procedan de buena fe. Además, este efecto protector de la buena fe es coherente con el conjunto del Código Civil, donde se premia a la buena fe no sólo en la posesión estableciendo presunciones a su favor (por ejemplo, en el artículo $434 \mathrm{Cc}$ ), sino también en otras instituciones como es la prescripción adquisitiva, requiriendo plazos menores para su consumación cuando concurre este requisito (artículos 1955 y 1957). En definitiva, nos atrevemos a decir que debe primar la apariencia sobre la realidad si el objetivo es fomentar la economía y la seguridad del tráfico.

Segundo, y como consecuencia de lo anterior, también se apoya en este trabajo la tesis dualista de los artículos 32 y 34 de la Ley Hipotecaria con base a los mismos argumentos. Desde luego que, en base a lo expuesto y desde mi punto de vista, ha de 
rechazarse el dualismo extremo, pues es inimaginable que nuestro Derecho admitiese adquisiciones a non domino sin concurrir la buena fe. Entre las dos posturas restantes, el dualismo medio y el moderado, personalmente me inclino más por el dualismo moderado, pues como afirmaba la Exposición de Motivos de la Ley de reforma hipotecaria de 1944 "Es preferible qué el adquirente gratuito deje de percibir un lucro, a que sufran quebranto económico aquellos otros que, mediante legitimas prestaciones, acrediten derechos sobre el patrimonio del transmitente".

En definitiva, en mi opinión la reserva de dominio debería ceder en este tipo de adquisiciones cuando se cumplan con los requisitos comentados previamente. Al margen de ello, no podemos obviar la realidad y como hemos apuntado falta una concreción por parte del legislador en estos preceptos que abarcan una materia esencial en la vida de un Estado y que provoca inseguridad jurídica en una cuestión tan trascendental como es ésta. Sea como fuere, y sin ánimo de extender más esta obra, parece ser que nos adentramos, aunque a ritmo lento, a alcanzar una postura común en cuanto a la naturaleza de la reserva de dominio sobre la base de la teoría clásica de la que cabe esperar, quizá por ser el punto de partida, una regulación que abarque otros aspectos controvertidos de esta figura.

\section{Bibliografía.}

- ALBALADEJO GARCÍA, M. (2011), Derecho Civil II. Madrid: Edisofer.

- AMORÓS GUARDIOLA, M. (1972), "El pacto de reserva de dominio en los bienes inmuebles". Revista crítica de derecho inmobiliario. $\mathrm{n}^{\circ}$. 488, pp. 9-42.

- BALLARÍN MARCIAL, A. (1949), "El Registro de la Propiedad español. Separata de la «Revista Crítica de Derecho Inmobiliario», por Rafael Núñez Lagos”. Anuario de Derecho Civil, pp. 676-686.

- DÍEZ-PICAZO, L. (1983), Fundamentos del Derecho Civil Patrimonial, volumen II. Madrid: Tecnos.

- DÍEZ-PICAZO, L. (2008), Fundamentos del Derecho Civil Patrimonial, volumen III. Madrid: Civitas.

- DÍEZ-PICAZO, L. (2010), Fundamentos del Derecho Civil Patrimonial, volumen $I V$. Navarra: Civitas.

- ESPEJO LERDO DE TEJADA, M. (2006), La reserva de dominio inmobiliaria en el concurso. Navarra: Civitas

- GARCÍA GARCÍA, J. M. (1993), Derecho inmobiliario registral o hipotecario, tomo II. El concepto de tercero. Inoponibilidad. Fe pública. Prioridad. Madrid: Civitas.

- GARCÍA VICENTE, J. R. (2013), “Artículo 1257 del Código Civil” en BERCOVITZ RODRÍGUEZ-CANO, R. (Dir.) Comentarios al Código Civil, tomo VI. Valencia: Tirant lo blanch. pp. 9027-9033. 
- GORDILlO CAÑAS, A. (2004), "El principio de inoponibilidad: el dualismo moderado de nuestro sistema inmobiliario registral". Anuario de Derecho Civil, pp. 381-548.

- LACRUZ BERDEJO, J. L. y SANCHO REBULLIDA, F. (1984), Derecho inmobiliario registral, elementos de Derecho Civil, III bis. Barcelona: Bosch.

- MIQUEL GONZÁLEZ, J. M. (1993), “Artículo 464 del Código Civil” en DÍEZPICAZO, L., BERCOVITZ, R.y Otros (Dirs.) Comentario del Código Civil del Ministerio de Justicia. Madrid: Ministerio de Justicia. Centro de Publicaciones. pp. 1240-1249.

- MIQUEL GONZÁLEZ, J. M. (2012), "La reserva de dominio" en BOSCH CAPDEVILA, E. (Dir.) Nuevas perspectivas del derecho contractual. Barcelona: Bosch. pp. 139-224.

- OCAÑA RODRÍGUEZ, A. (2000), "La reserva de dominio. Naturaleza y efectos más importantes" en NIETO CAROL, U. (Dir.): La Ley de Venta a Plazos de Bienes Muebles. Valladolid: Lex nova. pp. 139-201

- PAU PEDRÓN, A. (1993), “Artículo 606 del Código Civil” en DÍEZ-PICAZO, L., BERCOVITZ, R.y Otros (Dirs.) Comentario del Código Civil del Ministerio de Justicia. Madrid: Ministerio de Justicia. Centro de Publicaciones. pp. 1532-1536

- PEÑA BERNALDO DE QUIRÓS, M. (1999), Derecho reales. Derecho hipotecario. Tomo II: derechos reales de garantía. Registro de la Propiedad. Madrid: Civitas

- PINO ABAD, M. (2015), "La cláusula de reserva de dominio en los contratos de venta de bienes muebles con precio aplazado" en MORILLAS JARILLO, M. J.; PERALES VISCASILLAS, M. y Otros (Dirs.) Estudios sobre el futuro Código Mercantil: Libro homenaje al profesor Rafael Illescas Ortiz. Getafe: Universidad Carlos III de Madrid, pp. 1720-1739

- RIVERA FERNÁNDEZ, M. (1994), La posición del comprador en la venta a plazos con pacto de reserva de dominio. Valencia: Tirant lo blanch.

- RODRÍGUEZ-ROSADO, B. (2004), “Cobro de lo indebido, tradición y usucapión: estudio de los artículos 464 y 2897 del Código Civil y 35 de la Ley Hipotecaria”. Anuario de Derecho Civil, no. 3, 1003-1104

- RODRÍGUEZ-ROSADO, B. (2009), “"Ius ad rem" y condena de la mala fe: una explicación de los artículos 1473, 1295.2 y 1124.4 del Código civil”. Anuario de Derecho Civil

- SABORIDO SÁNCHEZ, P. (2008), Reflexiones sobre el tercero hipotecario. Madrid: Centro de Estudios Registrales. 
- SÁEZ RUIZ, J. L. (2015), Tesis doctoral: La reserva de dominio de bienes muebles.

- SÁNCHEZ CALERO, F. J. y SÁNCHEZ-CALERO ARRIBAS, B. (2015), Manual de Derecho Inmobiliario Registral. Valencia: Tirant lo blanch. 